\title{
A LA SOMBRA DEL ÉXITO. EL PINTOR ANTONIO SÁNCHEZ GONZÁLEZ Y SU ACTIVIDAD EN LA IGLESIA MADRILEÑA DEL SALVADOR (1801-1804)
}

\author{
Juan Alejandro Lorenzo Lima*
}

\section{RESUMEN}

Este artículo da a conocer las intervenciones del pintor tinerfeño Antonio Sánchez González en la iglesia del Salvador de Madrid, donde realizó una nueva decoración al fresco para las pechinas del crucero y diseñó el retablo mayor. Además de recordar su trayectoria, analiza la situación del maestro antes de la Guerra de la Independencia (1808) y el pleito que dichos trabajos motivaron en la Real Academia de Bellas Artes de San Fernando, ya que no contaban con la aprobación de los pintores Gregorio Ferro y Mariano Salvador Maella ni de los arquitectos Juan Pedro Arnal, Juan de Villanueva y Antonio López Aguado, entre otros. Palabras Clave: retablo, tabernáculo, pintura, fresco, Academia de Bellas Artes, Comisión de Arquitectura, Antonio Sánchez González.

\section{IN THE SHADOW OF SUCCESS. THE PAINTER ANTONIO SÁNCHEZ GONZÁLEZ AND HIS ACTIVITY IN THE CHURCH OF THE SALVADOR IN MADRID (1801-1804)}

\section{Abstract}

This paper deals with the works of the painter from Tenerife Antonio Sánchez González in the church of El Salvador in Madrid, where he made a new fresco decoration for the pendentives of the transept and designed the main altarpiece. In addition to recalling his carrer, the study analyzes the situation of the artist before the War of Independence (1808) and the lawsuit that these actions motivated in the Royal Academy of Fine Arts of San Fernando, where they didn't have the approval of the painters Gregorio Ferro and Mariano Salvador Maella or the architects Juan Pedro Arnal, Juan de Villanueva and Antonio López Aguado, among others.

KeYwords: altarpiece, tabernacle, painting, fresco, Academy of Fine Arts, Architecture Commission, Antonio Sánchez González. 
La trayectoria vital y profesional del pintor Antonio Sánchez González (17581826) estuvo condicionada por dos hechos significativos: ser yerno de su maestro Juan de Miranda (1723-1805) y trasladarse a Madrid en 1789, a buen seguro con la intención de ganar una notoriedad que no iba a brindarle el trabajo acometido antes en Tenerife. Lo paradójico de esa coyuntura es que conocemos poco acerca de las circunstancias en que se desenvolvió su vida y del vínculo que mantuvo con el taller de Miranda, donde es sabido que aprendía el oficio en $1775^{1}$. Años después contrajo matrimonio con Andrea Miranda, única hija del artífice, y desde al menos 1786 dirigió una escuela de dibujo que los miembros de la Real Sociedad Económica de Amigos del País promovieron a instancia suya en La Laguna ${ }^{2}$. Él había nacido en Santa Cruz de Tenerife y coincidió en dicho obrador con el también aprendiz Santiago Domínguez Acevedo, natural del Puerto de la Cruz y de quien no sabemos nada en firme hasta el momento. Es probable que los primeros ańos de su actividad estuvieran ligados al taller de Miranda, en el que maestro y discípulos atendieron una demanda creciente y de identificación dificultosa ${ }^{3}$.

Las incertidumbres al respecto son muchas, ya que no disponemos de noticias sobre creaciones de Sánchez González y desligarlas de la producción mirandesca se torna en un asunto complejo por ahora. Ignoramos cuál es el paradero de unos retratos que al parecer terminó en Garachico durante 1787 y de un lienzo no muy bien resuelto de la Adoración de los pastores, que firmó también y copiaba otro de gran formato e igual tema que su suegro había concluido para la parroquia matriz de Santa Cruz en $1773^{4}$. Además, dos pinturas sobre plancha de cobre que se le asignaban, una representación de la Virgen de Guadalupe y otra de la Virgen de la Providencia, conservadas en domicilios de La Orotava, son en realidad un trabajo firmado por el maestro homónimo y de origen novohispano Antonio Sánchez ${ }^{5}$. Irremediablemente, su obra documentada del periodo insular se limita a dos frontales que pintó y doró hacia 1788 para la iglesia de la Concepción de La Laguna, cuya pista perdemos a raíz de reformas acometidas en dicho templo décadas más tarde ${ }^{6}$.

* Doctor en Historia del Arte. http://orcid.org/0000-0001-9016-2529; https://independentresearcher.academia.edu/JuanAlejandroLorenzoLima.

1 Padrón Acosta, Sebastián (1945): «El pintor Antonio Sánchez González», La Tarde, 28/7/1945.

2 Tarquis Rodríguez, Pedro (1954): «Antonio Sánchez. Su permanencia en La Laguna», La Tarde, 27/1/1954.

${ }_{3}$ Rodríguez GonzÁlez, Margarita (1986): La pintura en Canarias durante el siglo XVIII. Las Palmas de Gran Canaria, Cabildo de Gran Canaria, pp. 294-368, 468-472.

4 Padrón Acosta, Sebastián (1945): «El pintor...», art. cit.; Padrón Acosta, Sebastián (1945): «Un óleo de Antonio Sánchez», La Tarde, 22/9/1945.

5 Amador Marrero, Pablo F. (2006): «Dos cobres del pintor novohispano Antonio Sánchez en Canarias», Anales del Instituto de Investigaciones Estéticas, 88, pp. 205-212, con bibliografía previa.

6 Tarquis Rodríguez, Pedro (1954): «Antonio Sánchez...», art. cit.; Rodríguez GonZÁLEZ, Margarita (1986): La pintura..., op. cit., p. 469. Para contextualizar esas intervenciones arquitectónicas y la contribución de Sánchez a ellas, consistente en la pintura de capillas laterales, el órgano, el oratorio y los presbiterios, véase Lorenzo Lima, Juan Alejandro (2016): «Una fábrica 
Tal coyuntura prueba que nuestro conocimiento sobre el trabajo de este autor es escaso a todos los niveles, por lo que resulta imposible advertir los derroteros de su estilo y cuanto derivó de él en un medio proclive a la regeneración de las artes. Desde luego, lo que sabemos no guarda relación con la fama de «hábil» e «inteligente» que los ilustrados tinerfeńos le atribuyeron antes de mudar la residencia a Madrid?.

El panorama no cambia con lo sucedido tras el viaje a la Península. Algunos documentos señalan que su marcha coincide con la partida del comandante general Miguel de la Grúa Talamanca, marqués de Branciforte, a quien Miranda había retratado años antes junto a los enfermos del hospicio de San Carlos ${ }^{8}$. Lejos de Canarias, su trayectoria estuvo supeditada a la posibilidad de convertirse en pintor de cámara, tal y como lo refieren varias peticiones que elevó a los reyes Carlos IV y Fernando VII entre 1797 y 1826. Lo único que ganaría entonces fue el cargo de pintor adornista con un sueldo módico en 1825, pero, como dedujo Hernández Perera, al final de su vida ello no le reportaba fondos suficientes para mantener a una familia que había aumentado tras casar de nuevo y tener varios hijos?

Entre los méritos señalados una y otra vez en sus memoriales se encontraban haber conspirado a favor de la política absolutista y trabajos de diversa consideración que afrontó como decorador en palacios que estuvieron a cargo de la corona. Un requerimiento de 1823 lo describe como defensor del absolutismo durante el Trienio Liberal, señalando, incluso, que sufrió una causa penal que lo mantuvo durante algo más de dos años «encerrado y sin más recursos que los de la providencia»" Él mismo refería los encargos que atendió de forma esporádica en varias estancias de Aranjuez, El Escorial y La Florida a partir de 1791, aunque la crítica reconoce tan solo su contribución al ornato de los jardines de La Florida a finales de la década de $1810^{11}$.

$\mathrm{Al}$ igual que sucede con tantos coetáneos, la estabilidad laboral y personal de un maestro secundario como Sánchez González fue menor a raíz de la invasión francesa de 1808. Una carta del administrador Juan José Blesa informa que la guerra le sorprendió en Madrid, mientras residía y trabajaba en el palacio de La Florida. En él los militares «robaron y rompieron cuantas preciosidades y muebles contenía, sin atreverse a chistar ningún dependiente»; por ello mismo, de la destrucción no esca-

construida y reconstruida a lo largo del siglo xviri. Reformas, proyectos y arquitectos de la parroquia», La Laguna y su parroquia matriz. Estudios sobre la Iglesia de la Concepción. La Laguna, Instituto de Estudios Canarios, pp. 53-149.

7 Lorenzo Lima, Juan Alejandro (2016): «Arte y artistas en los inicios de la Real Sociedad Económica de Amigos del País de Tenerife», Lux Nivariensis. La Real Sociedad Económica de Amigos del País de Tenerife en su 260 aniversario. La Laguna, Real Sociedad Económica de Amigos del País de Tenerife, pp. 91-93.

8 Tarquis Rodríguez, Pedro (1954): «Antonio Sánchez. Su salida de Santa Cruz de Tenerife», La Tarde, 28/1/1954.

9 Hernández Perera, Jesús (1958): «Antonio Sánchez González, pintor adornista y conspirador», Anuario de Estudios Atlánticos, 3 (1957), pp. 165-204.

${ }_{10}$ Archivo General de Palacio, Madrid (en adelante AGP): Personal. Sign. 966/21.

11 Fernández Talaya, María Teresa (1999): El Real Sitio de la Florida y La Moncloa. Evolución histórica y artística de un lugar madrileño. Madrid, Fundación CajaMadrid, pp. 313-314. 
paron su casa ni las posesiones y otras herramientas que dejó en dicha fábrica, tras «haberse fugado de la capital para no sucumbir a tales monstruos». La imposibilidad de volver al trabajo en palacio queda de manifiesto cuando el mismo Blesa comunicó al pintor que ignoraba «lo que vendrá a pasar con este embarazo tan envuelto de misterios que debemos disponer a padecer $\aleph^{12}$.

El dominio galo cambió las expectativas profesionales del artista y, tras un tiempo prudencial de espera, lograba huir hasta la ciudad de Cádiz, donde fue testigo de acciones impulsadas por los miembros de la Junta Suprema primero y por los diputados de las Cortes luego ${ }^{13}$. No ha podido calibrarse la contribución de Sánchez a proyectos que surgieron en aquel entorno tras el hito constitucional de 1812, porque, entre otros asuntos, sabíamos que en una carta dirigida a sus allegados de Tenerife comunicó que bosquejaba ya una serie de representaciones sobre sucesos contemporáneos en tono alegórico ${ }^{14}$. Conviene profundizar en ello y en otros trabajos suyos que permanecen inéditos, puesto que la prensa gaditana se hizo eco de festejos organizados en torno a las Cortes y su repercusión artística. Un apunte del diario de sesiones, relativo a mayo de 1812 , informa que fue autor de un dibujo que representaba «los hechos más principales ocurridos en la Península desde el día 2 de mayo de 1808 hasta en el que se publicó la Constitución $»^{15}$. No es casual, pues, que en 1815 el pintor de cámara Vicente López (1772-1850) exaltara su «buena moralidad» y «arreglada conducta», informando que Sánchez había atendido «bastantes trabajos en su emigración de esta corte a Cádiz cuando la invasión francesa ${ }^{16}$.

Paradójicamente, ese reconocimiento que el artista ganó entre absolutistas y liberales no guarda relación con lo sucedido antes de 1808, cuando transcurre el episodio que nos ocupa en este artículo: un largo pleito que propiciaron las reformas dirigidas por Sánchez González en el oratorio o iglesia del Salvador, un templo de estima entre los madrileños de aquella época. La documentación generada por esta disputa no es amplia ni refiere todo su desarrollo con la claridad deseada, pero, en cambio, resulta útil a la hora de conocer la situación en que se encontraba el pintor, la valoración negativa que tuvieron sus realizaciones y la dinámica surgida a su alrededor en el seno de la Academia de San Fernando. A estos asuntos dedicaremos los epígrafes que siguen, aportando datos nuevos para comprender mejor la trayectoria de un maestro tan errático e incomprendido en nuestro tiempo.

12 AGP: Personal. Sign. 966/21.

13 Hernández Perera, Jesús (1958): «Antonio Sánchez...», art. cit., pp. 178-184.

14 Tarquis Rodríguez, Pedro (1955): «Antonio Sánchez González, pintor de cámara. Cuestión del Consulado del Mar», Hoja oficial del lunes, 29/11/1955 y 19/12/1954.

${ }_{15}$ Diario de sesiones de las Cortes Generales y Extraordinarias. Cádiz, 1/V/1812. Una contextualización de esa y otras iniciativas semejantes en De la Mano, José Manuel (2008): «Goya intruso: arte y política en el reinado de José I», Goya en tiempos de guerra [catálogo de la exposición homónima]. Madrid, Museo del Prado, pp. 55-81.

16 AGP: Personal. Sign. 966/21. 


\section{EL ARTISTA Y LA IGLESIA DEL SALVADOR. UN PROYECTO DE RETABLO EN 1802}

En las memorias que Sánchez González elevó a Fernando VII para ganar el favor regio explicaba que su marcha a la Península la motivó un único deseo: dar continuidad a los estudios de dibujo y pintura en la Real Academia de Bellas Artes de San Fernando, superando con ello su labor como docente en La Laguna y lo que llamó a menudo «decadencia de las artes» en Tenerife. Esa determinación no contradice las que fueron sus primeras acciones en Madrid, porque, precisamente, en diciembre de 1789 quedó inscrito como alumno de San Fernando ${ }^{17}$. Desconocemos su evolución o trayectoria posterior en dicho centro al no figurar entre los estudiantes que obtenían reconocimiento a finales de siglo y participaban en los concursos de pintura que sus regentes convocaron antes de $1808^{18}$. Es probable que ciertas limitaciones y la imposibilidad de acudir a clases presenciales por su edad avanzada no le ayudaran a ganar el aval académico, algo que décadas antes y por otros motivos ocurrió también con su suegro Juan de Miranda ${ }^{19}$.

Sea como fuere, en 1797 Sánchez González elevó una petición al rey Carlos IV para convertirse en supernumerario de ayuda de la furriera, sin recibir por ello sueldo u otra gratificación. Para avalar esa distinción honorífica que no lograría entonces, argumentó su trayectoria previa en Tenerife y «el privilegio de estar empleado en las obras de pintura [de la corte] hace cuatro ańos», no una carrera estimable al amparo de la Academia ${ }^{20}$. En ese tiempo el oratorio del Salvador demandaba una atención que no era ajena a las inquietudes profesionales de maestros secundarios como Sánchez, quienes encontraron en este tipo de fábricas y en sus responsables a potenciales clientes o patrocinadores. Dicha iglesia era un edificio notorio, de gran volumen y muy popular entre los fieles de Madrid por quedar emplazado en la céntrica calle de San Bernardo. Su origen se vincula a la orden de los jesuitas, ya que junto al seminario o noviciado anexo responde a una fundación alentada a principios del siglo Xvir por la piadosa Ana Félix de Guzmán, hija del primer conde de Olivares y mujer del segundo marqués de Camarasa. Tras la expulsión de 1767 el templo se convirtió en una iglesia diocesana y, después de barajar otras opciones, las autoridades eclesiásticas acabaron cediendo su culto y cuidado a los padres misioneros del Salvador ${ }^{21}$.

17 Hernández Perera, Jesús (1958): «Antonio Sánchez...», art. cit., p. 172; Pardo CanaLís, Enrique (1961): Los registros de matrícula de la Academia de San Fernando de 1752 a 1815. Madrid, CSIC, p. 202.

${ }^{18}$ Cfr. AA. VV. (1994): Historia y alegoria: los concursos de pintura de la Real Academia de Bellas Artes de San Fernando (1753-1808). Madrid, Academia de Bellas Artes de San Fernando.

${ }^{19}$ Lorenzo Lima, Juan Alejandro (2011): «Juan de Miranda en la Academia. El artista y su participación en el concurso de pintura de 1760", Estudios Canarios. Anuario del Instituto de Estudios Canarios, 55, pp. 173-206.

${ }^{20}$ AGP: Personal. Sign. 966/21.

${ }^{21}$ Marín Perellón, Francisco José (2009): «La manzana del Noviciado entre los siglos XVI y xIX», El Noviciado de la Universidad en Madrid: 1836-1846. Madrid, Consorcio Urbanístico de 
Dichos clérigos integraron una comunidad o congregación de carácter secular, aunque su regla fundacional de 1644 permitía la unión de algunos seglares a «un instituto tan útil para la piedad y el beneficio de los fieles de Madrid». La sede anterior fue una casa estrecha e inmediata a la cárcel de Corte, de modo que el cambio ya citado de inmueble y la reforma de sus constituciones, aprobada por el papa Clemente XII en 1734, les hizo ganar un protagonismo mayor durante el periodo de la Ilustración. Las prácticas recurridas por la corporación eran el desarrollo de ejercicios espirituales, la confesión y expiación de culpas, el rezo comunitario del rosario, la explicación de la doctrina y, fuera del templo, la asistencia continua a hospitales y cárceles, fomentando con ello un sentido caritativo que no era ajeno al reformismo de las Luces ${ }^{22}$.

Ese contexto es el que nos interesa ahora, ya que en su exitoso Viaje de España Antonio Ponz (1725-1792) describe el estado del complejo jesuita y la adecuación del edificio subsistente a tales fines. Aunque refiere al oratorio del Salvador como una fábrica "cómoda» y de "buena proporción" por la planta de cruz latina, su presbiterio y otros espacios de culto mostraban un ornato antiguo, impropio para las exigencias de gusto neoclásico que demandaba ya la Academia. No extraña, pues, que censurara la situación del altar mayor, señalando que en él «parece que se llevó la idea de figurar una porción de anfiteatro, con alusión a San Ignacio»; y luego señala que dicha obra tenía «en la parte inferior una selva de columnitas con muchos leones en el zócalo, sin duda porque fue echado a estas fieras». Concluye afirmando que todo ese ornato respondía a «un pensamiento ridículo y mezquino en la ejecución, que también se puso en práctica en las capillas colaterales dentro del presbiterio ${ }^{23}$.

La decoración descrita y el "gran cuadro» que presidía el altar principal, obra del pintor del siglo XVII Simón de León Leal, no guardaban relación con los nuevos ideales estéticos ni con el tipo de culto que se practicó en el templo, puesto que los misioneros del Salvador alentaron en fecha temprana las novedades del catolicismo ilustrado o religiosidad de corte racional que propugnaban los jansenistas. Por eso mismo no extraña otro comentario que Ponz incluyó en su Viaje, al advertir que «todo esto se quitará cuando los padres [...] tengan proporción de hacerlo y pondrán retablos de buena arquitectura, como el que hicieron construir en el oratorio antiguo ${ }^{24}$. Lo más probable es que esa afirmación del erudito ilustrado, antes secretario de la Academia, recogiera un deseo que pudo conocer al visitar el templo de forma reiterada o entablar contacto con los religiosos. Fuera o no así, lo cierto es que ese proyecto no resultó ajeno a la trayectoria del padre Antonio Quintana,

la Ciudad Universitaria de Madrid, pp. 51-62; Fernández, Gonzalo (2011): «Los principales ejemplos de la herencia jesuítica en la provincia de Madrid y la ciudad de Guadalajara y sus vínculos con la Universidad Complutense», Espacio Tiempo y Forma. Serie II (Historia Antigua), 24, pp. 573-586.

22 Sastre Santos, Eutimio (1983): «La madrileña Congregación de Misioneros Seculares del Salvador del Mundo y sus primeras constituciones», Hispania Sacra, XXXV-72, pp. 529-584.

${ }^{23}$ Ponz, Antonio (1793): Viaje de España: cartas, en que se da noticia de las cosas más apreciables, y dignas de saberse que hay en ella. Madrid, Viuda de Joaquín Ibarra, t. v, p. 190.

${ }_{24}$ Ponz, Antonio (1793): Viaje..., op. cit., pp. 190-191. 
quien, como último responsable del oratorio, alentó la renovación del presbiterio y de otras estancias del inmueble durante los primeros años del siglo xix. No obstante, después de 1767 los mismos sacerdotes habían colocado en el altar mayor «un trono de nubes con ángeles mancebos», que talló en madera Manuel Álvarez (1721-1797) y servía de base a "una estatua del Salvador que ya tenían [...] en su antiguo oratorio $»^{25}$.

En ese contexto de cambios resulta primordial Antonio Sánchez González, porque, si nos limitamos a la declaración posterior de Quintana, fue el artista quien se ofreció a la congregación de misioneros para afrontar la ejecución de una propuesta nueva y responder así a todas las necesidades que implicaba el proyecto reformista. De ahí que el propio Quintana enviara a la Academia de San Fernando un diseño de altar y tabernáculo realizado por el maestro tinerfeño, cuya recepción no tuvo lugar hasta el 4 de marzo de $1802^{26}$. Cuatro días después, los miembros de su Comisión de Arquitectura valoraban el proyecto e informaron de inmediato sobre la reprobación, comunicando que para validar una obra de tanto alcance era indispensable «la formación de un nuevo dibujo, que debería encargarse a un arquitecto aprobado y presentarse después a censura de la Academia». Solo si obtenían el visto bueno de ese otro diseño, los religiosos "podrían proceder a la construcción de la obra [...] por ajustarse a él $\aleph^{27}$. La disconformidad de los comisionados fue tan notoria que, incluso, en la comunicación de Silvestre Pérez (1767-1825) sobre el acuerdo adoptado en la Comisión de Arquitectura del día 5, señalan que la traza firmada por Sánchez eludía «las reglas constitutivas y elementales del arte» ${ }^{28}$.

No sabemos lo que ocurrió semanas después, pero, desde luego, una resolución tan desfavorable enojó al padre Quintana y a los integrantes de la congregación ${ }^{29}$. Los trámites que iban a sucederse con el diseño de un nuevo conjunto no favorecían la inmediatez del proyecto y, lo que era peor aún, generaba un mayor volumen de gastos para la economía precaria de los religiosos y sus fieles. Por todo

25 Ponz, Antonio (1793): Viaje..., op. cit., p. 191. A pesar de lo que algunos autores manifestaron antes, la escultura y el basamento tendrían que haberse reutilizado en el noviciado tras la mudanza de 1767. La intervención de Álvarez está documentada en 1766, siendo consecuencia de un diseńo previo de Ventura Rodríguez (1717-1785) para el templo de la calle de la Cárcel. Se conserva un dibujo de esta pieza, al ser recurrida como tema para la prueba de pensado en el concurso de la tercera categoría de Arquitectura durante 1769. Cruz YÁbar, María Teresa (2011): El escultor Manuel Álvarez (1721-1797) [tesis doctoral]. Madrid, Universidad Complutense, pp. 275-278/n . 33 . Al no conocerse la obra de 1802-1804 que estudiamos ahora, parecía lógica la reutilización del conjunto previo de Rodríguez que tanto elogiaron Ponz y otros contemporáneos. Cruz YÁbar, María Teresa (2017): «Los retablos de Ventura Rodríguez», Ventura Rodríguez. Arquitecto de la Ilustración [catálogo de la exposición homónima]. Madrid, Comunidad de Madrid, p. 196; AA. VV. (2018): Ventura Rodríguez. El poder del dibujo. Madrid, Comunidad de Madrid, p. 283.

${ }^{26}$ Archivo de la Real Academia de San Fernando (en adelante AASF): Sign. 2-34-2. Pieza 2, documentos sin clasificar. La carta del religioso figura firmada el 4 de marzo y fue leída en una junta ordinaria que los académicos celebraron luego. AASF: Sign. 2-34-3, documento 1.

${ }^{27}$ AASF: Sign. 2-34-2. Pieza 2, documentos sin clasificar.

${ }_{28}$ AASF: Sign. 2-34-3, documento 2.

${ }_{29}$ Conocieron la respuesta a su primera petición tras una carta enviada desde la Academia el 8 de marzo de 1802. AASF: Sign. 2-34-3, documento 3. 
ello los padres del oratorio desoyeron la recomendación de los académicos y dieron inicio a la obra durante los últimos meses de 1802, si bien los miembros de la junta de San Fernando no tendrían conocimiento de una determinación así hasta principios del año siguiente. En junta celebrada el 2 de enero de 1803 acordaron que la ejecución del retablo debía suspenderse de inmediato, ya que «se estaba construyendo [...] no solo por un sujeto no aprobado, sino también por la misma traza que había sido reprobada por este real cuerpo ${ }^{30}$.

Decidieron escribir al padre Quintana con el fin de que valorara unas acciones tan negligentes, cuya consecuencia principal era el incumplimiento de reales órdenes y edictos que regían la materia ${ }^{31}$. El arquitecto de San Fernando Juan Pedro Arnal (1735-1805) se comprometió a visitar el templo y reconocer lo edificado allí sin licencia, pero, habiendo ido a comprobar las medidas del sitio unos días antes, «se le negó la entrada a la iglesia en que efectivamente se construía dicho retablo por el plan reprobado ${ }^{32}$. Sin quererlo, el pleito entre los religiosos y los académicos adquiría un sentido nuevo y propició el intercambio de valoraciones contrarias al respecto.

\section{EL POLÉMICO ALTAR DE ANTONIO SÁNCHEZ}

La documentación preservada en la Academia sobre el retablo del Salvador no describe la organización que tuvo en el diseño ni sus rasgos principales, aunque una memoria posterior ayuda a valorar ciertas cualidades que mostraba en lo funcional y lo arquitectónico. Tampoco aclara la participación efectiva de Sánchez González en su materialización, pero, si nos atenemos a lo expresado por el padre Quintana tras el requerimiento de la Academia, queda claro que la voluntad del pintor propició que se trabajara de forma clandestina en el conjunto de altar y tabernáculo. Los acontecimientos no dejaron de sucederse en los días siguientes, porque, como era previsible, los padres del oratorio recibieron una carta del consiliario de San Fernando Pedro Silva donde disponían de información acerca de la normativa que incumplió el deseo de erigir un retablo nuevo sin consentimiento. La nómina de órdenes y edictos es bastante completa en ese sentido, ya que los académicos aludieron a los estatutos de la entidad de 1757, a la Real Orden de 1777 que controlaba el desarrollo de las construcciones eclesiásticas, otra Real Orden de 1784 que renovaba en parte a la anterior y, sobre todo, la Real Orden de 1791 acerca de las fábricas para el culto y los retablos que se encontraba en vigor, cuyo conocimiento era generalizado en todos los territorios del reino. Con ello los dirigentes de la junta quisieron remarcar su atribución y potestad para el control de las edificaciones reli-

\footnotetext{
${ }^{30}$ AASF: Sign. 2-34-2. Pieza 2, documentos sin clasificar.

31 AASF: Sign. 2-34-2. Piezas 1 y 2, documentos sin clasificar.

32 AASF: Sign. 2-34-3, documento 4.
} 
giosas, una meta que no lograron hasta que la comisión ya aludida de arquitectura pudo establecerse en $1786^{33}$.

Lo que más enojó al padre Quintana fue la descalificación que los académicos hicieron de Antonio Sánchez y de las cualidades de su trabajo, siempre censurables. En varias cartas llegarían a referirlo como un «sujeto que no solo no estaba examinado de arquitecto, sino que jamás se le había conocido estudiar ni seguir esta profesión». En ese sentido sorprende que no aludieran a su paso por la Academia, porque, al margen de que fuera más o menos prolongado en el tiempo, el pintor pudo adquirir nociones de dibujo y diseńo tras su llegada a Madrid. El silencio al respecto resulta inquietante, pero no lo es menos saber que el pleito adquirió entonces una dinámica compleja, cuya resolución no posibilitaban las opiniones contradictorias e irreconciliables que expresaron ambas partes. Viendo que su reclamación no iba a tener efectividad entre los padres del Salvador, la junta de San Fernando envió un informe al arzobispado de Toledo para no interponer un recurso a la congregación, ya que, según explican, sus miembros eran «celosos del buen orden y de una exacta obediencia de la reales determinaciones». Intuyeron que lo sucedido hasta el momento no habría que entenderlo como una resistencia premeditada, sino, más bien, como una actitud contraria a la normativa en vigor por desconocimiento o despiste ${ }^{34}$.

La contestación del padre Antonio Quintana no se hizo esperar y el 25 de enero de 1803, cuatro días después de leer el oficio de Silva, remitió una larga carta a los dirigentes de San Fernando donde explicaba lo ocurrido hasta el momento. $\mathrm{Su}$ relato es el previsible, pero, más allá de lo que podríamos valorar como una disculpa común, tiene el interés de poner de manifiesto la debilidad y las incongruencias de normas que regulaban la práctica artística bajo el sentido ortodoxo y canónico de la Academia. No sorprende que comenzara su exposición defendiendo la actividad de Sánchez González, maestro con el que debió entablar amistad antes de que el proyecto pudiera materializarse en un plano a finales de 1801 o principios de 1802. Reconoce que la traza fue encargada a este pintor por acuerdo unánime de los miembros del oratorio y que, salvo por algunas modificaciones que llevó a cabo para la mayor perfección, gustó a todos los implicados en la empresa. Es más, reconoce que su intención no era «hacer una obra que compita con las de los grandes maestros y [...] sea modelo de enseñanza, sino una que, no siendo monstruosa ni mezquina, esté arreglada al arte».

Quintana sobreentendía que esa aspiración sí la lograba el diseño invalidado de Sánchez, por lo que no dudó en presentarlo al arzobispo de Toledo para su aprobación. Comenta al respecto que «no solo le agradó, sino que [...] lo describió facultativamente y [...] dio licencia para ejecutarlo». Por ello no tardó en entregar la traza con una pequeña memoria al viceprotector de la Academia Bernardo de Iriarte

33 BéDat, Claude (1986): La Real Academia de Bellas Artes de San Fernando (1744-1808). Madrid, Fundación Universitaria Española, pp. 371-398; García Melero, José Enrique (1996): «El control de la arquitectura española: la Comisión de Arquitectura de la Real Academia de Bellas Artes de San Fernando", Butlleti de la Reial Acadèmia Catalana de Belles Arts de Sant Jordi, 10, pp. 75-98.

${ }^{34}$ AASF: Sign. 2-34-3, documento 4. 
para que fuese autorizado, no esperando que, como ya sabemos, los comisionados de arquitectura acabaran reprobándola en 1802. Lo que sucedió luego es conocido y, aunque en un principio se negó a que Juan Pedro Arnal revisara la obra, permitió que finalmente accediese a medir el presbiterio y conociera lo previsto allí. El padre Quintana explica que el mismo Arnal no quiso corregir el plano de Sánchez y, tras explicarle sus deseos de realizar una obra modesta, «marchó prometiendo hacer sin interés un diseño». Informa que hasta en tres ocasiones discípulos suyos acudieron a tomar medidas en el templo, por lo que decidió suspender los trabajos «con notable perjuicio para el acopio de los materiales». Tras ocho meses de espera, recurría a «un sujeto de mucho respeto para [incentivar] a este profesor», pero con ello no logró respuesta ni una solución a la coyuntura vivida entonces.

El parón forzoso de las obras, sin alternativa posible de ejecución a corto plazo, era un sinsentido que no comprendieron Quintana ni los miembros de su comunidad, ya que el templo permanecía sin un presbiterio en condiciones tras desmontar el retablo previo de madera. Esa circunstancia motivó que contactara con el arquitecto mayor Juan de Villanueva (1739-1811), a quien pedía en vano que cuidase de la obra para que "no se cometiera absurdo». Sin embargo, ni una ni otra medida fueron llevadas a la práctica y el asunto siguió unas semanas más en suspenso. Su descontento con los arquitectos académicos y las alternativas que se ofrecían resultan lógicas y comprensibles, hasta el punto de que los argumentos esgrimidos ponen de relieve la inviabilidad del proceso administrativo, su inoperancia para dar soluciones con inmediatez y, sobre todo, la lentitud de los trámites burocráticos a la hora de corregir proyectos reprobados o en curso de ejecución.

El padre Quintana afirma con razón que, si una real provisión de 1801 aconsejaba no malgastar el dinero en obras indeseables, su procedimiento había sido el correcto para seguir tal fin en el presbiterio del Salvador. Pensaba que los textos legales y el vacío que se dio en circunstancias como la suya no debían frenar la ejecución del nuevo retablo de su templo, porque, al fin y al cabo, no perseguía otro objetivo que hermosear y solemnizar un lugar de culto. Considera que la idoneidad no reside siempre en los modelos propuestos o canónicos, ya que, invocando la relatividad del gusto, «un diseño [...] tan excelente y perfecto no me acomodaría midiéndolo con mis facultades». No faltaba razón al religioso, quien, además, creyó acertada la determinación de derribar la obra preexistente y contar para ello con el auxilio de Sánchez González. Tras varios meses de espera por la propuesta de Arnal, recurrió al pintor tinerfeño para evitar «el costo de un director académico, que por el honor que tiene y el que la obra exige, según costumbre, [implicaba] un jornal considerable » ${ }^{35}$.

No escatimó esfuerzos y, ante una situación tan compleja, él y sus compañeros planearon con Sánchez el inicio de la obra. La iniciativa era una aspiración añorada desde que los padres de su congregación se hicieron cargo de la iglesia jesuita en 1767, puesto que el mismo Quintana lo reconoce de forma explícita:

35 AASF: Sign. 2-34-3, documento 6. 
Hace años que veía con dolor el retablo mayor de mi iglesia, monstruo de arquitectura, y no podía derribarlo por falta de medios para fabricar otro, pero ya por uno de aquellos arrojos que parecen temerarios, fiado solamente en la piedad de los fieles y contando con mis pocos intereses, se me brindaba don Antonio Sánchez para hacerme gratuitamente un plano y ayudarme en todo gratuitamente [...], sin el menor interés ${ }^{36}$.

El ofrecimiento de nuestro autor, en principio desinteresado, era una garantía de ejecución para los religiosos, quienes lo defendieron así siempre. Ante la falta de entendimiento con la Academia y una espera frustrada por el proyecto de Arnal, el propio Antonio Quintana no contrató a arquitecto ni a aparejador de confianza. Su única alternativa era «Sánchez y otros mozos hábiles en diversas facultades, porque - explica intencionadamente- les merecía cariño, convidándose en todo con amor y por devoción a esta casa». Argumenta también que la normativa no sanciona de forma explícita la formación en arquitectura de cualquier tracista, ya que en última instancia el rey «no puede prohibir [...] un entendimiento y una obra de poca consideración como un retablo, que se enumera entre las de ornato, en una iglesia pobre como ésta y más cuando lo hacen gratuitamente" ${ }^{37}$.

Un razonamiento así disgustó mucho a los académicos. El mismo sacerdote señalaba que el problema no recaía solo en la cualificación del tracista, puesto que cualquier pieza o manufactura era el mejor aval para enjuiciar sus cualidades:

Esto lo dicta la razón, porque no es la mano la que se reconoce sino la obra. Vuestras señorías saben muy bien que ni los exámenes ni las academias dan talentos, y que ha habido ingenios cultivados por sí mismos que han brillado en las artes y han excedido a los grandes maestros sin tales exámenes ni academias. No intento persuadir [...] que Sánchez sea de esta clase, pero sí le aseguro que no he conocido a ninguno que como don Antonio Sánchez tenga más gusto y extensión de conocimiento en todas las artes; $y$ estoy en que pregunten al que ejecute bien para juzgar de sus obras en donde ha estudiado, es creer que las aulas dan entendimiento.

Quintana no enumera o describe otros trabajos de nuestro artífice, pero la defensa de sus operarios de confianza le impidió seguir con una obra que se encontraba en este estado:

aún no hay puesta ni una sola pieza del retablo, porque parece que era la ocasión de impedirlo cuando se viese el todo o parte puesta con las deformidades que teme y quiere precaver la Academia, a quien aseguro seré yo el primero que concurra en derribarlo cuando se oponga a las órdenes de $S[\mathrm{u}] \mathrm{M}[\mathrm{ajestad}][\ldots]^{38}$.

\footnotetext{
36 AASF: Sign. 2-34-2. Pieza 2, documentos sin clasificar.

37 AASF: Sign. 2-34-2. Pieza 2, documentos sin clasificar.

38 AASF: Sign. 2-34-3, documento 6.
} 
Irremediablemente, el retablo se quedaba sin posibilidad de ser materializado a partir de la traza denostada de Sánchez. Tocaba esperar y buscar otras alternativas para obtener finalmente un diseńo que contentara a las partes implicadas en el pleito.

\section{MÁS ALLÁ DEL RETABLO. OTRAS ACTUACIONES PICTÓRICAS DE SÁNCHEZ}

La confianza que Antonio Quintana y los clérigos de la congregación depositaron en Antonio Sánchez la reflejan otras empresas que el maestro ideaba para el templo, en un principio de forma gratuita. Sin embargo, los acontecimientos que sucedieron luego y la repentina muerte de Quintana motivarían que en $1806 \mathrm{el}$ pintor reclamara en vano el pago de todos sus trabajos en la fábrica ya renovada del oratorio $^{39}$. Gracias a ello sabemos que al tiempo o poco después de trazar el retablo que iba a presidir de nuevo una "estatua del Salvador que [...] tenían los padres", no la «pintura antigua» de San Ignacio, intervino en el «ornato general» de un edificio que aunaba el patrimonio heredado de los jesuitas con nuevas adquisiciones o donaciones.

Ese hecho es otro aspecto clave del litigio que nos ocupa, quizá no destacado lo suficiente en documentos de la Academia. Como pintor al servicio de la congregación, Sánchez pudo intervenir o retocar muchas obras que conservaba el entonces oratorio del Salvador. Antonio Ponz describe en su Viaje de España que dicha iglesia exhibía un volumen notorio de bienes, entre los que destacaron varios del establecimiento jesuita incautados en 1767 y $1835^{40}$. Esculturas de todo tipo decoraban sus retablos, recibiendo un elogio comedido algunas manufacturas italianas y una «efigie moderna» de San Miguel que Luis Salvador Carmona (1708-1767) había tallado para que presidiera su propia capilla; y en lo referente a pintura, Ponz recuerda que el noviciado contó con creaciones estimables de Francisco Rizi (16081685), Diego González de la Vega (1628-1697), Juan Niño de Guevara (1632-1698) y Jacopo Amigoni (1682-1752), conservadas ahora entre la Universidad Complutense y el Museo del Prado ${ }^{41}$.

Mayor significación revestía el ciclo de pinturas que Michel-Ange Houasse (1680-1732) dedicó antes de 1722 a San Francisco Regis y colgaba junto al retablo de dicho santo en el crucero; y lo mismo cabría decir de varios lienzos que décadas antes contrató Simón de León Leal (... 1631-1700), maestro muy desconocido en nuestro tiempo y a quien tanto elogiaron Díaz del Valle, Palomino, Ponz y Ceán Bermúdez. De su autoría eran, entre otros, «el cuadro grande [...] del altar mayor que representa el martirio de San Ignacio obispo» y la decoración de la cúpula y de

39 AASF: Sign. 2-34-2. Pieza 2, documentos sin clasificar.

40 Miguel Alonso, Aurora (2007): «Los bienes de la Compañía de Jesús incautados en Madrid en 1767 y 1835, y conservados en la Universidad Complutense», La desamortización: el expolio del patrimonio artistico y cultural de la Iglesia en España. Madrid, Ediciones Escurialenses, pp. 413-432.

${ }^{41}$ Ponz, Antonio (1793): Viage..., op. cit., pp. 189-194. 
toda la bóveda del templo, donde se colocó un total de «veintiuna pinturas de la infancia del Salvador», así como de "otros asuntos sagrados» ${ }^{42}$.

Precisamente, León Leal ornamentó las pechinas de la cúpula que cubría el crucero. Su trabajo allí fue reemplazado por unas representaciones nuevas de Sánchez González que motivaron opiniones diferentes entre los fieles y algunos «entendidos en el arte». Por eso mismo, para calibrar si su labor debía ser remunerada o no, la Academia designó a varios maestros que reconocieron la iglesia y evaluaron el alcance de las figuraciones de nuestro artífice. Sin embargo, la consecución de esa empresa que coordinaba el marqués de la Espeja como viceprotector de San Fernando no pudo solventarse de forma inmediata. El pintor Francisco Javier Ramos (17461817) excusó la comisión por hallarse imposibilitado con «unos dolores reumáticos desde le hueso sacro hasta la pierna derecha». Ante ello, no quedó otra posibilidad que contar con la opinión autorizada de los también pintores Gregorio Ferro (17421812) y Mariano Salvador Maella (1739-1819).

La memoria que el primero emitía al respecto en junio de 1807 es escueta, pero, además de repetir los elogios que Palomino hizo de León Leal, concluyó que las nuevas representaciones de Sánchez eran «malas»" ${ }^{43}$. Más elocuente se manifestaba Maella, quien recordó en primer momento las pinturas realizadas en el templo «por el profesor d(o)n León Leal, sujeto de mucho mérito». A él asigna la autoría de "los cuadros que tiene pintados en el techo del cuerpo de la iglesia», asegurando que «son mejores, sin comparación, que los actuales [de Sánchez], en los que no se halla composición, claroscuro, dibujo ni buen colorido, por cuyas circunstancias carecen de efecto». Concluye que «no hay mérito en dichas pechinas, no pudiendo menos de decir [...] que hay obras desagradecidas» ${ }^{44}$. Juicios de ese calibre, emitidos por artistas de renombre en el estatus académico, manifiestan las limitaciones del autor tinerfeño a la hora de enfrentarse a repertorios figurativos de pintura mural, no recursos simples como adornista o decorador en los que ya empezaba a especializarse con trabajos de poco alcance en los complejos palaciegos de Aranjuez, El Escorial y La Florida.

\section{CON POSTERIORIDAD. UN RETABLO QUE VUELVE A SER POLÉMICO}

A pesar de que el padre Antonio Quintana y otros religiosos de la congregación expresaron su voluntad de materializar el diseño de retablo previsto por Sánchez, la determinación de la Academia y de las autoridades eclesiásticas lo impidió de forma inmediata. Viendo que la propuesta de los clérigos contradecía su opinión,

42 Ponz, Antonio (1793): Viaje..., op. cit., pp. 192-193; Ceán Bermúdez, Juan Agustín (1800): Diccionario histórico de los más ilustres profesores de las Bellas Artes en España. Madrid, Viuda de Ibarra, t. III, pp. 13-15.

43 AASF: Sign. 2-34-2. Pieza 3, documentos sin clasificar.

${ }_{44}$ AASF: Sign. 2-34-2. Pieza 3, documentos sin clasificar. 
los responsables de San Fernando escribieron al arzobispo de Toledo para explicar lo ocurrido hasta entonces ${ }^{45}$. Por lo tanto, fue Luis María de Borbón, miembro de la alta jerarquía hispana y uno de los eclesiásticos más influyentes del país, quien ordenó a Quintana descartar el conjunto de altar y tabernáculo planificado antes, reunir el material disponible y elevar una nueva propuesta a la Academia. Ese proyecto tenía que encomendarse a un arquitecto aprobado, cuya labor estuvo medida desde entonces por el «aprovechamiento [...] de las piezas que ya estaban construidas» $y$, sobre todo, «el control y la dirección posterior de la obra ${ }^{46}$.

Una determinación así dio al traste con las aspiraciones conjuntas de Quintana y Sánchez González, quien en su diseño pudo remedar los modos o esquemas de corte barroco que mostraban otros retablos del templo para conferir unidad al presbiterio en el orden estético. Alusiones posteriores a su decoración inservible y a curvas en la planta, no líneas o volúmenes rectos como exigía el gusto nuevo, pudieron motivarla la influencia del altar que se erigía en el crucero de la antes iglesia jesuita: el retablo de San Francisco de Regis, instalado después de 1862 en el templo del monasterio de las Descalzas Reales. Se trata de un conjunto vistoso e importante del tardobarroco italiano, que fue construido con diseño de Agostino Cornacchini (1686-1754) y exhibe aún las esculturas originales de Camilo Rusconi (1658-1728) y tal vez Bernardino Cametti (... 1669-1736) ${ }^{47}$. Lo que nadie imaginaba entonces es que esa búsqueda de la unidad estética con el pasado, tan contraria al mensaje de la Academia, invalidaría también la segunda propuesta de retablo mayor que se previó para El Salvador.

La fábrica del altar era ya un asunto controvertido y, ante la aparente insubordinación de los religiosos y de Sánchez, a la junta de San Fernando no le quedó otro remedio que medir bien las acciones e intervenir de modo ejemplar. Si erraban en sus determinaciones el asunto iba a tornarse en un escándalo público, porque, atendiendo a la relevancia y a la proximidad del inmueble de culto, quedaría en evidencia la incapacidad del medio académico para controlar y gestionar las nuevas obras de arquitectura. Ante ese temor, perceptible también en ejemplos coetáneos de la periferia madrileña y de Andalucía, los académicos actuaron al unísono y registraron sus decisiones con una precisión inusual. De ahí que en febrero de 1803 acordaran escribir al arzobispo por medio del marqués de Solana, el marqués de Peñafiel y, muy especialmente, el también canario Estanislao de Lugo y Molina, director de los Estudios de San Isidro y académico de honor de San Fernando desde $1793^{48}$. No entraremos en disquisiciones surgidas tras un acuerdo adoptado al respecto en junta del 6 de febrero de 1803, aunque días después el mismo Lugo reprochaba a Isidoro Bosarte, secretario de la Academia, que los miembros de la comisión hubiesen actuado con «demasiada blandura, absteniéndose en el proyecto de representa-

45 AASF: Sign. 2-34-2. Piezas 1 y 3, documentos sin clasificar.

46 AASF: Sign. 2-34-3, documentos 14-16.

47 AA.VV. (2002): Retablos de la Comunidad de Madrid. Madrid: Comunidad de Madrid, pp. 308-309, con bibliografía precedente.

48 AASF: Sign. 2-34-3, documentos 7-9. 
ción [...] el descender a impugnar y rebatir los ridículos pretextos que [los religiosos] alegan para su resistencia» ${ }^{49}$.

El asunto se tornaba por momentos en una disputa larga y enrevesada, ya que, además, los arquitectos Juan de Villanueva y Juan Pedro de Arnal excusaron una implicación mayor en el pleito ${ }^{50}$. No obstante, el arzobispo Luis María de Borbón comunicaba al marqués de la Espeja, entonces viceprotector de la Academia, su intención de prohibir el diseño de Sánchez y de que «la obra nueva se ejecute siguiendo la traza que debía entregar [Juan Pedro] Arnal, de quien -advierte- hago la mayor confianza por su notoria inteligencia y acierto en obras de esta clase». Razones para un juicio así no faltaban, puesto que Arnal había intervenido en varios proyectos de La Mancha y prestado servicios a las catedrales de Jaén, Burgos y Málaga, entre otros edificios de culto relevantes ${ }^{51}$. Satisfecho con una determinación así, el mismo eclesiástico ordenó

que no se aumenten gastos y que ni la casa ni su celoso presidente [entiéndase Quintana] puedan sufrir encaminando todos sus ideas y prudente discernimiento a que no se malogre el tiempo, [el] trabajo y [los] utensilios comunicados en la construcción de un altar y retablo que, aunque no salgan absolutamente ajustados a las reglas del arte, siempre quedarán con mejor gusto y servirán con más decoro para la celebración del santo sacrificio y demás funciones del santo templo que los antiguos desmontados y destruidos como inútiles para fines tan sagrados ${ }^{52}$.

Al tiempo de conocer la determinación del arzobispo y las explicaciones que la Academia ofreció sobre ellas, Antonio Quintana remitió otro diseño para el examen de la Comisión de Arquitectura. Sin embargo, a diferencia de lo previsto inicialmente, la segunda propuesta de retablo no respondió a la autoría de Juan Pedro Arnal o de los arquitectos más aventajados de San Fernando. El clérigo confió esa tarea al maestro de obras Alfonso de Vargas, cuya traza, entregada el 28 de abril, no ganó la aprobación de los académicos unos días más tarde ${ }^{53}$. Ante ello, la comisión encomendó el diseño definitivo al arquitecto Antonio López Aguado (1764-1831), discípulo de la Academia. Dicho autor dibujó dos modelos diferentes que, como era de esperar, obtuvieron el visto bueno de los miembros de la junta de San Fernando el 18 de mayo de $1803^{54}$. Fue entonces cuando valoraron la adecuación de su altar a los rigores de nuevo estilo, señalando que con las curvas y otros adornos superfluos la propuesta de Vargas «abunda en defectos casi tanto como la que inventó Sánchez».

49 AASF: Sign. 2-34-3, documento 9.

50 AASF: Sign. 2-34-3, documentos 10-13.

51 SAmbricio, Carlos (1986): La arquitectura española de la Ilustración. Madrid, Consejo Superior de los Colegios de Arquitectos de España e Instituto de Estudios de Administración Local, pp. 304-310.

52 AASF: Sign. 2-34-3, documento 17.

53 AASF: Sign. 2-34-3, documentos 18-19.

${ }^{54}$ Esa actuación y otras de igual responsabilidad, conocidas solo por los acuerdos de la Comisión de Arquitectura, las refirió antes SAmBricio, Carlos (1986): La arquitectura..., op. cit., pp. 350-353. 
El trabajo no había sido fácil, porque, según refieren algunos documentos, López Aguado tuvo que corregir errores, depurar el estilo y, sobre todo, «aprovechar [...] lo que ya está hecho según el primer plano [de Sánchez] que se reprobó»" 55 ; y por si habían dudas al respecto, un acuerdo adoptado el 17 de mayo refiere que, tras la dirección del pintor tinerfeño, podía «aprovecharse lo más esencial y menos malo de la obra, la cual ya está labrada y dispuesta a colocarse en su lugar».

$\mathrm{El}$ «retrato» que dicho arquitecto hizo del conjunto es muy elocuente en ese sentido:

La planta del presbiterio y de la iglesia donde se ha de colocar este retablo, compuesta de formas rectas y sencillas, ofrecía que se continuase este sistema en el altar para que guardase unidad esta parte principal con el todo de la iglesia; pero el A [plano reprobado de Sánchez], huyendo de toda regularidad, invirtió la planta del presbiterio y estableció la del altar en formas curvas, cóncavas y convexas, cuyo partido mal combinado es el extremo a que puede llegar la depravación y el mal gusto de la arquitectura; y las columnas, pudiéndolas situar exentas, las pegó a los muros como si necesitasen otro apoyo que el suyo propio.

En el alzado se advierte el inútil pedestal que disminuye la grandiosidad que pudieran tener las columnas si no se apoyaran sobre aquel suplemento, como también en el marco detrás de la imagen principal, sobre ser absolutamente superfluo y que solo tendría lugar cuando hubiera que guarnecer alguna pintura. Está además mal proporcionado, lleno de resaltos y de festones pueriles, perfilado sin gusto y con demasiada pesadez.

La elección de un romanato [alero] para conclusión del altar es lo más pobre y material que puede ofrecer el arte, pues así como es oportuna y significante su colocación en lo exterior de los templos porque representa su tejado, es impropia y fuera de razón en los interiores que ya están cubiertos y por medio libres de la intemperie.

Al tabernáculo le asisten otros defectos de racionalidad a los del altar: planta complicada, arquitrabes apoyados en falso, resaltes inútiles y molduras tortuosas ${ }^{56}$.

Con argumentos de este tipo, nadie dudó que las propuestas de López Aguado eran una alternativa segura para materializar el retablo e instalarlo en el presbiterio sin demora, corrigiendo, además, los defectos de la proyectiva debida a Sánchez y Vargas. Las acciones en ese sentido no se hicieron esperar, de modo que en junta de 5 de junio de 1803 los académicos designaron a Matías Gutiérrez como responsable de materializar su ejecución de forma exacta y puntual ${ }^{57}$. Sin embargo, cuando el consenso llegó a todas las partes, no tardaron en surgir las discrepancias de nuevo. Tras estudiar el diseño de Aguado y calcular los costes de materiales y

55 AASF: Sign. 2-34-2. Pieza 2, documentos sin clasificar. Sign. 2-34-3, documento 21.

56 AASF: Sign. 2-34-2. Pieza 2, documentos sin clasificar.

57 AASF: Sign. 2-34-3, documento 22. 
salarios, el padre Quintana y los religiosos del oratorio pidieron su suspensión al no tener fondos para construirlo $y$, tal vez por influencia del pintor tinerfeńo, siempre en la sombra, pidieron a la desesperada que se les concediera permiso para "colocar el retablo hecho según el plano de don Antonio Sánchez y que éste lo dirija hasta su conclusión, respecto a hacer él esto gratuitamente y a haberse costeado de limosnas, como también atendiendo a que no será posible concluir la otra por falta de dinero ${ }^{58}$.

Desde luego, los académicos no esperaban este revés; y, para colmo de males, la reclamación de Quintana se puso en conocimiento del rey Carlos IV, quien pedía a los dirigentes de San Fernando un dictamen con el fin de evaluar esa postura y no transgredir con ello «el honor y el decoro de las artes». Sin quererlo, el ya polémico retablo del Salvador entraba en su última fase o periodo de realización.

\section{LA CONSTRUCCIÓN DEL ALTAR. SÁNCHEZ ES VETADO FINALMENTE}

Ante el contratiempo surgido con la última solicitud de los religiosos, la Academia dio respuesta a un requerimiento tan descabellado para contentar al rey y demostrar la idoneidad del proyecto de López Aguado. En septiembre de 1803 ese mismo arquitecto y Arnal se comprometieron a hacer un estudio de la inviabilidad económica del plan de Sánchez, expresando el último que los cambios más notables se centraban en la apertura de un nicho mayor para la escultura del Salvador que iba a presidirlo y en la definición del remate. De acuerdo con lo previsto por Aguado y Gutiérrez, tenía que eliminarse la cornisa ornamentada y el gran frontón, ya que esa pieza era "de muy mal gusto por la confusión de molduras de que se compone».

En su memoria refiere también algunas modificaciones que

son de mucha consideración y consisten en suprimir las ráfagas que circundan al Salvador, el marco que está lleno de una talla costosa y de mal gusto, y el tabernáculo, que no estando principiado ni teniendo prevenido material alguno, se ha dispuesto en su lugar otro más sencillo y proporcionado que el mostrado en el primer diseño por hallarse aquél lleno de perfiles ridículos propios de un ignorante, y en el que se iban a malgastar 15000 reales que en el aprobado en el nuevo diseño.

El ahorro se cifró igualmente en 40000 reales más que, según cálculo de Arnal, "podían economizarse en todo lo demás del altar, suprimiendo la confusión de bajorrelieves y ridículas esculturas con que lo había adornado el profesor que las dispuso" $"$.

Los números no engañaban y, ante su conocimiento, Quintana y Sánchez pudieron alegar poco. Aguado informó más tarde que el ahorro superaba otros 11000 reales que iba a importar el nicho embutido en la pared con su arco de ladri-

58 AASF: Sign. 2-34-3, documento 24.

59 AASF: Sign. 2-34-3, documentos 25-27. 
llo, cuya colocación tuvo que variarse para situarlo a la altura del arquitrabe. En esa cantidad se englobaron también cuatro pilastras de fábrica, situando dos «dentro del mismo nicho» y otras dos «en la porción semicircular que forma el altar». A su vez, en lugar del amplio frontón iban a disponer «un zócalo liso sobre el que se han de colocar los [ángeles] mancebos y las ráfagas de gloria», reproduciendo un modelo de remate común para la retablística neoclásica. Sin ir más lejos, el propio Aguado introdujo ángeles orantes y elementos de la común "gloria» o «resplandor» en dos diseños de retablo que dibujó al mismo tiempo para la capilla de los Dolores de la catedral de Sevilla ${ }^{60}$.

La mayor discrepancia en cuanto a cifras se observa en el tabernáculo, de modo que la propuesta definitiva de Aguado suponía la inversión de al menos 340 pesos, es decir, un total aproximado de 29.000 reales de vellón. Su diseño eliminaba hasta cuatro columnas que eran innecesarias, medallas ornamentales con festones, cuatro ángeles y el remate "en forma de cordero con sellos y cruz». A cambio proponía la labra de tan solo «ocho columnas de mármol con basas y capiteles de bronce dorado a fuego", "cuatro grupos de coronas y palmas que deben colocarse en los cuatro medios», "cuatro festones para colocar en el [...] ático»y, como novedad, «los pámpanos, los racimos y la cruz que forman el remate» ${ }^{61}$.

Este tipo de juicios prueban que la simplicidad del gusto neoclásico era también un acierto en lo económico y lo funcional, de modo que el mismo Aguado concluyó su memoria señalando que «si el altar desde el principio se hubiese dirigido por un arquitecto de mérito conocido, hubiera sido una obra de mucho más lucimiento»; y desde luego, el costo no habría sido tan alto por «los disparates que el profesor ha cometido en el diseño del altar reprobado y tener que aprovechar lo que está hecho por mayor economía " ${ }^{62}$.

Poco más se podía argumentar al respecto, puesto que la memoria de dicho arquitecto, firmada el 15 de septiembre de 1803 y leída días después en la Academia, ganó el apoyo de los regentes de San Fernando y del propio rey, quien el 17 de octubre obligaba por fin a materializar lo contemplado en el diseño de López Aguado $^{63}$. A partir de aquí los documentos del pleito dejan de mencionar a Antonio Sánchez y su propuesta ya inviable para el retablo, a la que el padre Quintana tuvo que renunciar de forma obligada. No en vano, el 8 de noviembre dicho religioso se comprometía a ajustar la hechura del altar al proyecto sancionado últimamente por la Academia ${ }^{64}$.

${ }^{60}$ Recio Mir, Álvaro (1998): «Antonio López Aguado y los proyectos neoclásicos para el retablo de la capilla de los Dolores de la Catedral de Sevilla", Academia. Boletín de la Real Academia de Bellas Artes de San Fernando, 86, pp. 379-398.

${ }^{61}$ AASF: Sign. 2-34-3, documento 33.

${ }^{62}$ AASF: Sign. 2-34-3, documento 33.

${ }^{63}$ AASF: Sign. 2-34-3, documentos 34-36.

${ }^{64}$ AASF: Sign. 2-34-3, documentos 37-38. 
Lo sucedido después escapa a nuestro interés, ya que la participación del pintor tinerfeño en la construcción del retablo no era lógica ni justificable por razones obvias. De su materialización se encargó el ya aludido Matías Gutiérrez, quien en septiembre de 1804 informaba que "para la total conclusión no falta otra cosa que pintar y dorar dicho retablo, construir todo el tabernáculo, algunos bronces de la mesa y la colocación de todas las partes ${ }^{65}$. Informes de la Academia ratificaron entonces que «lo ejecutado [...] está con arreglo a los planos de López Aguado», por lo que Gutiérrez ganó la renovación en el cargo de maestro y director a pie de obra con un sueldo módico. Mucho tuvieron que aplicarse entonces Quintana y otros religiosos del oratorio en la búsqueda de fondos para dar acabado al retablo, algunos enseres litúrgicos que iban a completarlo y otras reformas del presbiterio, puesto que el término de dichas obras no fue posible con una limosna extraordinaria que habían solicitado al rey. Sin embargo, en noviembre de 1805, un año después, se comunicó de forma oficial el término del altar y del tabernáculo que presidía la ya renovada iglesia del Salvador. Los académicos quedaron satisfechos con el trabajo realizado por Arnal, Aguado y Gutiérrez para difundir el buen gusto y, a pesar de los muchos sinsabores del pleito, disponer de un referente válido ante empresas análogas que pudieran proyectarse en los templos del viejo Madrid $^{66}$.

Recibido: 6-4-2021; Aceptado: 15-4-2021

${ }^{65}$ AASF: Sign. 2-34-2. Pieza 1, documento sin clasificar.

${ }^{66}$ AASF: Sign. 2-34-2. Pieza 1, documentos sin clasificar. 
